\title{
Measurements of Reversible and Irreversible Inactivation Processes of a Redox Enzyme, Bilirubin Oxidase, by Electrochemical Methods Based on Bioelectrocatalysis
}

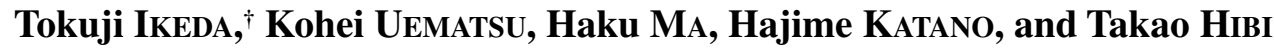 \\ Department of Bioscience, Fukui Prefectural University, Fukui 910-1195, Japan
}

\begin{abstract}
The inactivation of a redox enzyme, bilirubin oxidase (BOD), by heat and guanidine hydrochloride (GuHCl) was studied by two bioelectrochemical methods. One is a conventional method, which measures the inactivation of BOD in solution, and the other is a method using a BOD-immobilized electrode (a membrane/BOD/GC electrode), which measures the inactivation of BOD in the immobilized state. The results for thermal inactivation revealed that BOD both in solution and in the immobilized state obeyed the same irreversible inactivation kinetics. The CD and absorption spectra of BOD confirmed that the irreversible thermal inactivation was accompanied by a change in the secondary structure and the dissociation of type-1 copper from BOD. The measurements in the presence of $\mathrm{GuHCl}$ demonstrated that the BOD activity was significantly decreased at $1 \mathrm{M} \mathrm{GuHCl}$ in both states, and that the decrease proceeded reversibly. The CD spectrum of BOD indicated that the secondary structure of BOD was little affected by $\mathrm{GuHCl}$ at this concentration. The effect of $\mathrm{GuHCl}$ on the thermal inactivation was studied and evaluated as the resulting values of the Arrhenius activation energy: $\Delta G^{\neq}, \Delta H^{\neq}$, and $\Delta S^{\neq}$.
\end{abstract}

(Received September 16, 2009; Accepted October 14, 2009; Published November 10, 2009)

\section{Introduction}

Activity and stability are two important factors characterizing enzymes for their industrial use. Stability could be improved by the immobilization of enzymes through a series of trials and errors, ${ }^{1}$ and has been expected to be improved by means of protein engineering based on structural biology. ${ }^{2}$ In addition to the structural information, the kinetics and thermodynamics of enzyme inactivation would also be helpful for designing enzymes with higher stability and for a quantitative evaluation of the stability. The stability of an enzyme is usually evaluated as the residual activity under the optimum condition after being kept under a denaturing condition for a given period of time. ${ }^{3}$ Activity is mostly measured by a spectrophotometric method for recording an absorbance-time curve; the curve reflects any increase (or decrease) of the product (or substrate), and the initial slope of the curve is proportional to the enzyme activity. This is a method convenient for activity measurements of enzymes. However, the spectrophotometric method is tedious and time-consuming for the inactivation kinetics study; the method requires many times of the activity measurement under various conditions.

In the bioelectrocatalysis method, ${ }^{2,4,5}$ on the contrary, enzyme activity is measured as a time-independent steady-state bioelectrocatalytic current. The inactivation of an enzyme is simply measured as a time-dependent decrease in the current accordingly. In a previous paper, ${ }^{6}$ we proposed a bioelectrocatalysis method for recording an inactivation process

$\doteqdot$ To whom correspondence should be addressed.

E-mail: tikeda@fpu.ac.jp of a redox enzyme, bilirubin oxidase (BOD), and demonstrated that the method allows for the continuous measurement of the thermal inactivation process of the enzyme in solution. In this study, we extend the method to a method using an electrode with an immobilized-enzyme, a membrane/enzyme/electrode. ${ }^{7}$ The use of immobilized-biocatalyst electrodes has been reported for studies of the activation and deactivation of biocatalysts. ${ }^{8,9}$ The method is expected to provide a means for evaluating the stability of an enzyme under immobilized conditions. This is a method appropriate for enzymes designed for industrial use, because they are often used in their immobilized states. The method also allows for studies of the reversible nature of inactivation by a denaturant. The reversibility is easily judged by measuring bioelectrocatalytic currents at a membrane/enzyme/electrode before and after the addition of a denaturant in a solution, and again in a solution not containing the denaturant. In reversible inactivation, the current of the original magnitude will appear again in the last measurement. We use BOD as the redox enzyme to prepare a membrane/enzyme/electrode. BOD is a multicopper (one Type 1 , one Type 2 , and one set of Type 3 coppers) oxidase, which is a monomer of molecular weight 59950, composed of 534 amino acid residues containing one cysteine. ${ }^{10,11}$ The cysteine residue is bound to type- 1 copper as one of the ligands. ${ }^{12}$ BOD catalyzes the oxidation of bilirubin to biliverudin, ${ }^{10-13}$ and has been proved to be a promising enzyme as a cathode catalyst in biofuel cells, where $\mathrm{Fe}(\mathrm{CN})_{6}{ }^{4-}$ serves as an electron-transfer mediator between BOD and the cathode to reduce $\mathrm{O}_{2}$ into $\mathrm{H}_{2} \mathrm{O} .{ }^{14-17}$ First, we studied thermal inactivation of the immobilized BOD to compare with the inactivation of BOD in solution, ${ }^{6}$ and then the inactivation by guanidine hydrochloride $(\mathrm{GuHCl}) . \quad \mathrm{CD}$ and absorption spectra of BOD were measured under inactivating 
conditions to obtain structural information accompanied by inactivation. Finally, the effect of the denaturant on the thermal inactivation was investigated.

\section{Experimental}

\section{Reagents and chemicals}

Bilirubin oxidase (BOD; EC 1.3.3.5) from Myrothecium verrucaria was donated by Amano Enzyme Inc. (2.83 U/mg, Lot No. BOBO551301), which was stored at $-80^{\circ} \mathrm{C}$. One milliliter of a BOD solution was prepared with $50 \mathrm{mM}$ phosphate buffer ( $\mathrm{pH} 7.0)$, and the BOD concentration was determined spectrophotometrically using $\varepsilon_{600}=4800 \mathrm{M}^{-1} \mathrm{~cm}^{-1}$. ${ }^{12}$ The BOD solution was divided into 10 portions of $0.1 \mathrm{~mL}$ volume each, and stored at $-80^{\circ} \mathrm{C}$ until use. A $0.1-\mathrm{mL}$ portion of the BOD solution was brought to $0^{\circ} \mathrm{C}$ in ice and used up in a series of experiments on the same day. A stock solution of $5 \mathrm{mM}$ $\mathrm{Fe}(\mathrm{CN})_{6}{ }^{3-}$ was freshly prepared every two weeks from $\mathrm{K}_{3}\left[\mathrm{Fe}(\mathrm{CN})_{6}{ }^{3-}\right]$. GuHCl solutions of desired concentrations were prepared with $50 \mathrm{mM}$ phosphate buffer ( $\mathrm{pH}$ 7.0) using $\mathrm{GuHCl}$ of a grade for biochemical use (Wako Pure Chemical Industries, Ltd.), and the $\mathrm{pH}$ of the solution was readjusted to 7.0 with $1 \mathrm{M}$ $\mathrm{NaOH}$. All solutions were prepared with distilled water.

\section{Preparation of a membrane/BOD/GC electrode}

A $5-\mu \mathrm{L}$ aliquot of a BOD solution $\left(1.84 \times 10^{-5} \mathrm{M}\right)$ was dropped onto the surface of a glassy carbon (GC) electrode $(\phi=$ $3 \mathrm{~mm}$; BAS Co.), and the solvent was allowed to evaporate; then, the electrode was covered with a dialysis membrane (cutoff molecular weight of $12000-14000,20 \mu \mathrm{m}$ thick in the dry state; Spectrum Laboratories, Inc.). The whole electrode was covered with a nylon net to give it physical strength, and the membrane and net were fixed with a Teflon ${ }^{\circledR}$ ring to prepare the membrane/BOD/GC electrode.

\section{Apparatus and procedure}

Electrochemical measurements (voltammetry and amperometry) were carried out with a home-made electrochemical analyzer. The bare GC electrode or the membrane/BOD/GC electrode was used as the working electrode. A platinum coil and an $\mathrm{Ag} \mid \mathrm{AgCl}(0.1 \mathrm{M} \mathrm{KCl})$ electrode were used as the counter electrode and reference electrode, respectively. The potential is referred to as the $\mathrm{Ag} \mid \mathrm{AgCl}(0.1 \mathrm{M} \mathrm{KCl})$ electrode in the following. A home-made electrolysis cell of $10 \mathrm{~mL}$ volume with a water jacket was used, whose temperature was controlled by circulating water kept at a constant temperature with a water bath (Thermominder 50; Taitec Co.). The temperature of a test solution in the electrolysis cell was monitored with a digital thermometer (SK-250WP II-N, 15849; Sato Keiryouki Co.). All electrochemical measurements were carried out in air-saturated solutions. Each solution was stirred with a magnetic stirring bar in the measurements at a membrane/BOD/GC electrode, while the solution was kept quiet in the measurements at a bare glassy carbon electrode. UV-visible absorption spectra were measured with a JASCO V-630 spectrophotometer equipped with an EHC-477T temperature controller. Far-UV CD spectra were recorded with a JASCO J-720 spectrophotometer at room temperature. Each CD spectrum was the average of five scans. All spectra were corrected by subtracting the base line recorded with a solution of the same composition, except for BOD.

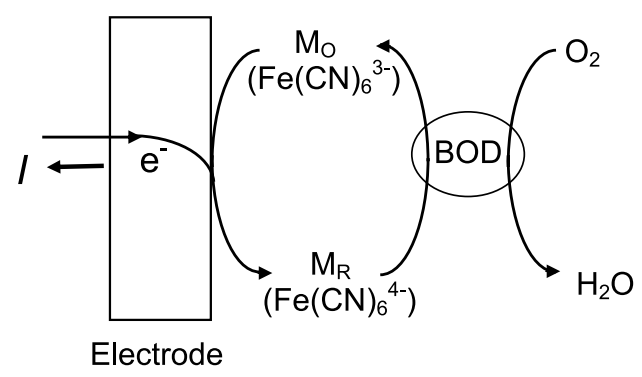

Fig. 1 Schematic illustration of the bioelectrocatalytic reduction of $\mathrm{O}_{2}$ by BOD with $\mathrm{Fe}(\mathrm{CN})_{6}{ }^{4}$ as a mediator.

\section{Results and Discussion}

\section{Theoretical considerations}

Figure 1 illustrates the bioelectrocatalytic reaction of BOD with $\mathrm{Fe}(\mathrm{CN})_{6}{ }^{4-}$ as a mediator. The limiting current, $I_{1}$, for the bioelectrocatalytic reaction is expressed by a theoretical equation, ${ }^{18}$ showing that $I_{1}$ is proportional to the square root of the concentration of BOD [BOD $]^{1 / 2}$ in a solution. We previously confirmed this proportionality. ${ }^{6}$

In the case of the enzyme immobilized on an electrode, the limiting bioelectrocatalytic current, $I_{1, \mathrm{im}}$, is given by ${ }^{19}$

$$
\frac{I_{1, \text { im }}}{F A}=\frac{k_{\text {cat }}}{K_{\mathrm{M}}}[\mathrm{BOD}] l \frac{\tanh \sigma}{\sigma}\left[\mathrm{Fe}(\mathrm{CN})_{6}{ }^{4-}\right],
$$

under the condition $\left[\mathrm{Fe}(\mathrm{CN})_{6}{ }^{4-}\right] \ll K_{\mathrm{M}}$. Here, [BOD] and $\left[\mathrm{Fe}(\mathrm{CN})_{6}{ }^{4-}\right]$ are the concentrations of BOD (enzyme) and $\mathrm{Fe}(\mathrm{CN})_{6}{ }^{4-}$ (mediator) in the enzyme layer on the electrode, respectively; $F$ and $A$ are the Faraday constant and the electrode surface area, respectively; $k_{\text {cat }}$ and $K_{\mathrm{M}}$ are the catalytic constant of the enzyme and the Michaelis constant of the mediator, the ratio, $k_{\mathrm{cat}} / K_{\mathrm{M}}$, being the bimolecular rate constant for the catalytic reaction of the enzyme; $l$ is the thickness of the enzyme layer, and $\sigma$ is a Thiele modulus defined by

$$
\sigma^{2}=\frac{\left(k_{\mathrm{cat}} / K_{\mathrm{M}}\right)[\mathrm{BOD}] l}{D_{\mathrm{M}} / l},
$$

where, $D_{\mathrm{M}}$ is the diffusion coefficient of the mediator in the enzyme layer. The magnitude of $\sigma$ for the membrane/BOD/GC electrode prepared in this study was calculated as 71 by the use of the following values for the respective quantities: $k_{\text {cat }}=$ $802 \mathrm{~s}^{-1},{ }^{16} K_{\mathrm{M}}=2.7 \times 10^{-6} \mathrm{M},{ }^{16}[\mathrm{BOD}] l=12.9 \times 10^{-10} \mathrm{~mol} \mathrm{~cm}^{-2}$, $l=8 \times 10^{-5} \mathrm{~cm}$, and $D_{\mathrm{M}}=6 \times 10^{-6} \mathrm{~cm}^{2} \mathrm{~s}^{-1}$. The $D_{\mathrm{M}}$ value is assumed to be equal to that in solution. The quantity [BOD] $l$ is calculated from the amount of BOD deposited on the GC electrode with $A=7.1 \times 10^{-2} \mathrm{~cm}^{2}$, and the $l$ value is calculated by assuming the closest packing of BOD (the radius is assumed to be $2.6 \mathrm{~nm}$ ). The actual thickness of the BOD layer would be larger than the $l$ value because of possible swelling of the enzyme and of a technical difficulty for realizing such a narrow enzyme layer on the electrode behind a dialysis membrane. When $l$ has a larger value, $\sigma$ becomes larger than the value calculated as mentioned above. In any case, noting that $\tanh \sigma \approx 1$ when $\sigma>2$, Eq. (1) in the present case is simplified to

$$
\frac{I_{1, \mathrm{im}}}{F A}=\sqrt{D_{\mathrm{M}} \frac{k_{\mathrm{cat}}}{K_{\mathrm{M}}}[\mathrm{BOD}]}\left[\mathrm{Fe}(\mathrm{CN})_{6}{ }^{4-}\right] .
$$




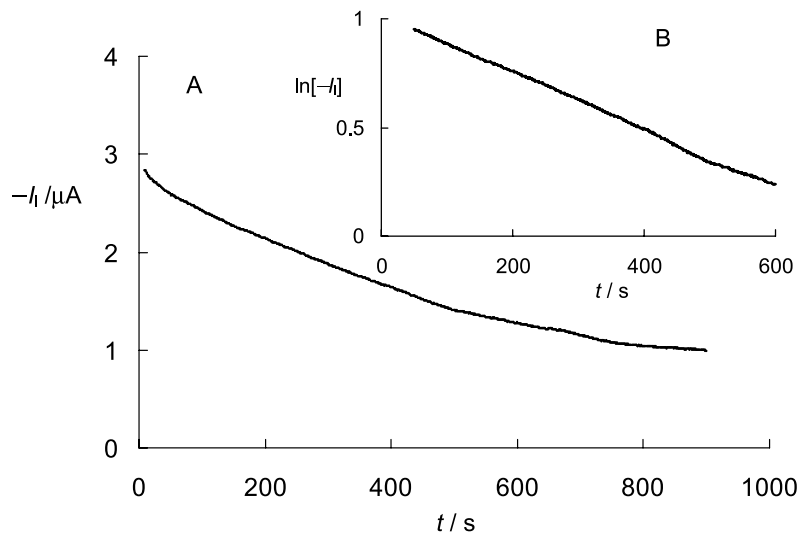

Fig. 2 A: Limiting current $\left(-I_{1}\right.$ at $\left.-0.2 \mathrm{~V}\right) v s$. time $t$ curve recorded with the membrane/BOD/GC electrode in $50 \mu \mathrm{M} \mathrm{Fe}(\mathrm{CN})_{6}{ }^{3-}$ phosphate buffer $\left(\mathrm{pH} \mathrm{7.0)}\right.$ at $60^{\circ} \mathrm{C} . \mathrm{B}: \ln \left[-I_{1}\right] v s$. time $t$ curve.

This equation predicts that the bioelectrocatalytic current at the membrane/BOD/GC electrode is also proportional to [BOD] ${ }^{1 / 2}$. Although Eq. (3) is valid only when $\left[\mathrm{Fe}(\mathrm{CN})_{6}{ }^{4-}\right]<K_{\mathrm{M}}$, as mentioned above, the proportionality is shown to be satisfied even when $\left[\mathrm{Fe}(\mathrm{CN})_{6}{ }^{4-}\right]>K_{\mathrm{M}} \cdot{ }^{18,20}$ Thus, the same expression as that of BOD in solution, ${ }^{6}$

$$
\ln \left[-I_{1}\right]=-(1 / 2) k t+\ln \left[-I_{1}\right]_{\mathrm{t}=0}
$$

is applicable to the inactivation kinetics at the membrane/BOD/ $\mathrm{GC}$ electrode; in this equation, $k$ is the rate constant for the inactivation reaction of the enzyme.

\section{Thermal inactivation}

Figure $2 \mathrm{~A}$ shows the current-time curve recorded with the membrane/BOD/GC electrode at $-0.2 \mathrm{~V}$ and at $60^{\circ} \mathrm{C}$ in a phosphate buffer $(\mathrm{pH} 7.0)$ containing $50 \mu \mathrm{M} \mathrm{Fe}(\mathrm{CN})_{6}{ }^{3-}$. The current, that is produced by the BOD-catalyzed reduction of $\mathrm{O}_{2}$ to $\mathrm{H}_{2} \mathrm{O}$, is decreased with time, reflecting the time-dependent inactivation of the immobilized BOD. The rate constant of the inactivation was determined to be $k=2.22 \times 10^{-3} \mathrm{~s}^{-1}$ from the slope of the linear regression line of the ln $k v s$. $t$ curve (Fig. 2B) by Eq. (4). Measurements at six different membrane/BOD/GC electrodes prepared in the same manner gave the average value of $k,(2.06 \pm 0.26) \times 10^{-3} \mathrm{~s}^{-1}(n=6)$. This $k$ value for the immobilized BOD agreed well with the value $(1.78 \pm 0.17) \times$ $10^{-3} \mathrm{~s}^{-1} \quad(n=5)$ for the inactivation of BOD in solution determined by a previously reported method. ${ }^{6}$ The results indicate that the thermal inactivation of BOD immobilized on electrode obeys the same kinetics as that of BOD in solution. The immobilization of an enzyme has often been employed as a means of improving its stability. ${ }^{1}$ The present result shows, however, that immobilization by the simple entrapment of BOD with a dialysis membrane has little effect on the stability. Thus, we may say that the electrochemical method using the membrane/BOD/GC electrode is useful for a stability evaluation of an enzyme in solution. We may also expect that the electrochemical method using an electrode with a differently prepared immobilized-enzyme would allow a quantitative evaluation of the immobilization effect on the stability. Electrodes with an immobilized-enzyme could be prepared by a number of immobilization methods, such as co-immobilization with other proteins, polysaccharides, and synthetic polymers. The irreversible nature of the thermal inactivation was confirmed

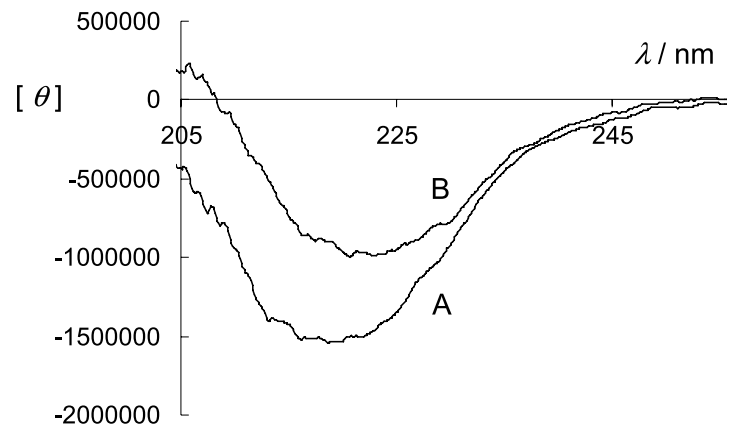

Fig. $3 \mathrm{CD}$ spectra of $\mathrm{BOD}\left(9.9 \times 10^{-7} \mathrm{M}\right)$ in $50 \mathrm{mM}$ phosphate buffer $(\mathrm{pH} 7.0)$ at room temperature $\mathrm{A}$, before and $\mathrm{B}$, after a treatment at $50^{\circ} \mathrm{C}$ for $2 \mathrm{~h}$. [ $\left.\theta\right]$ : molar ellipticity in deg $\mathrm{cm}^{2}$ decimole $^{-1}$.

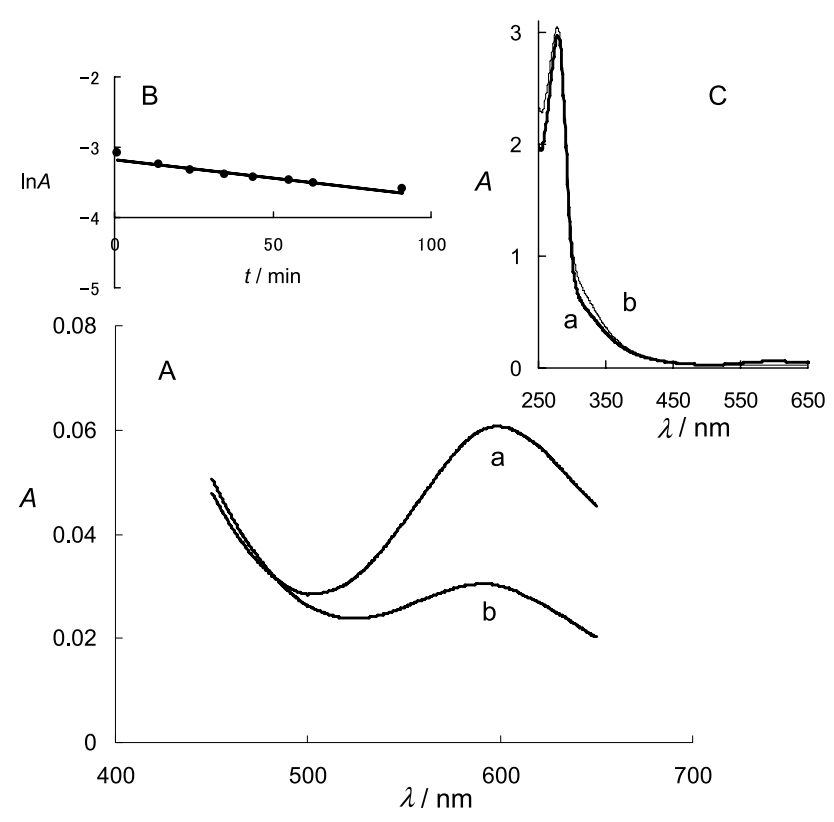

Fig. 4 A: Absorption spectra of BOD $\left(1.26 \times 10^{-5} \mathrm{M}\right)$ in $50 \mathrm{mM}$ phosphate buffer $(\mathrm{pH} 7.0)$ at $50^{\circ} \mathrm{C}$. The solution was kept at $50^{\circ} \mathrm{C}$ for (a) $1 \mathrm{~min}$ and (b) $91 \mathrm{~min}$ before recording the absorption spectra at the scan rate $400 \mathrm{~nm} / \mathrm{min}$. B: $\ln A($ at $600 \mathrm{~nm})$ vs. $t$ (the time held at $50^{\circ} \mathrm{C}$ ) plot. C: Absorption spectra in the range $250-650 \mathrm{~nm}$ of the same sample as A.

by an observation that when the membrane/BOD/GC electrode had been used once at $60^{\circ} \mathrm{C}$ for a kinetic measurement, the same electrode was no longer able to produce a current of appreciable magnitude for the bioelectrocatalytic reaction, even at room temperature.

Figure 3 shows the far-UV CD spectra of BOD (A) before and (B) after a treatment for $2 \mathrm{~h}$ at $50^{\circ} \mathrm{C}$, at which temperature the half-life of the thermal inactivation of BOD was $113 \mathrm{~min}^{6}$ Spectrum A shows a negative CD band at $219 \mathrm{~nm}$, as reported by Gotoh et al. ${ }^{21}$ The negative band is consistent with the molecular structure of BOD that contains many $\beta$-structures. ${ }^{22}$ When BOD was treated for $2 \mathrm{~h}$ at $50^{\circ} \mathrm{C}$, the negative band decreased in magnitude with a shift to $223 \mathrm{~nm}$. This decrease indicates that the thermal treatment causes a change in the secondary structure to a more flexible conformational state. The thermal treatment also leads to a decrease in the visible absorption spectrum of BOD at $600 \mathrm{~nm}$ (Fig. 4A), the absorption band being ascribed to type-1 copper (the site to accept 


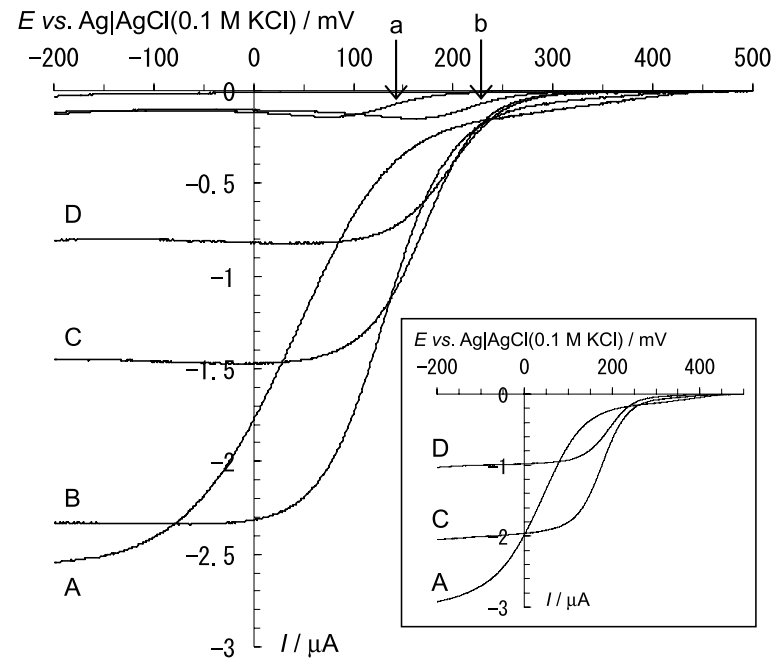

Fig. 5 Linear sweep voltammograms recorded with a bare glassy carbon electrode at $25^{\circ} \mathrm{C}$ in $50 \mathrm{mM}$ phosphate buffer $(\mathrm{pH} 7.0)$ containing $50 \mu \mathrm{M} \mathrm{Fe}(\mathrm{CN})_{6}{ }^{3-}, 0.6 \mu \mathrm{M}$ BOD and A - D, $0 \mathrm{M}, 0.1 \mathrm{M}$, $0.5 \mathrm{M}$, and $1.0 \mathrm{M} \mathrm{GuHCl} ; \mathrm{a}, 0 \mathrm{M}$ and b, $1 \mathrm{M} \mathrm{GuHCl}$ in the absence of BOD; scan rate, $2 \mathrm{mV} / \mathrm{s}$. The inset shows voltammograms at $35^{\circ} \mathrm{C}: \mathrm{A}$, $0 \mathrm{M}$; C, $0.5 \mathrm{M}$; D, $1 \mathrm{M} \mathrm{GuHCl}$.

electrons). ${ }^{12}$ Figure $4 \mathrm{~B}$ plots the time-dependent decrease of the absorbance $A$ at $600 \mathrm{~nm}$ as $\ln A$ against $t$. The rate constant calculated from the slope by the first-order kinetics is $1.2 \times$ $10^{-4} \mathrm{~s}^{-1}$, which agrees well with the rate constant, $(1.02 \pm 0.10) \times$ $10^{-4} \mathrm{~s}^{-1}$, determined previously ${ }^{6}$ for the inactivation of BOD at $50^{\circ} \mathrm{C}$ by the bioelectrocatalysis method. Figure $4 \mathrm{C}$ shows the absorption spectra in the range $250-650 \mathrm{~nm}$ of the same sample. No appreciable difference is observable between (a) and (b) in the whole spectrum, although the absorbace in the range $300-400 \mathrm{~nm}$ is slighly increased in (b). This result precludes the possibility of aggregate formation in an appreciable amount. Aggregates, if formed by inactivation, would cause a decrease in the whole spectrum due to their precipitation, or an increase due to scattering from the aggregates.

These spectrophotometric measurements reveal that the thermal inactivation of BOD is accompanied by a conformational change with the decrease in the secondary structure and by the dissociation of type-1 copper (or a structural change in the copper complex). The dissociation explains the irreversible nature of the thermal inactivation of BOD.

\section{Inactivation by $\mathrm{GuHCl}$}

Figure 5 shows the effect of $\mathrm{GuHCl}$ on the linear sweep voltammogram for the bioelectrocatalytic reaction of BOD in a solution at $25^{\circ} \mathrm{C}$. The bioelectrocatalytic current decreased with increasing concentration of $\mathrm{GuHCl}$; the magnitude of the limiting current, $I_{1}$ (measured at $-0.2 \mathrm{~V}$ ), decreased to $32 \%$ of the original magnitude at the $\mathrm{GuHCl}$ concentration of $[\mathrm{GuHCl}]=$ $1 \mathrm{M}$. When the measurements were carried out at 15 and $35^{\circ} \mathrm{C}$, a similar dependence of $I_{1}$ on $[\mathrm{GuHCl}]$ was obtained (the inset in Fig. 5 shows the result at $35^{\circ} \mathrm{C}$ ). Figure 6 shows voltammograms recorded with the membrane/BOD/GC electrode in a phosphate buffer containing $50 \mu \mathrm{M} \mathrm{Fe}(\mathrm{CN})_{6}{ }^{3-}$. The shape of the voltammogram in the absence of $\mathrm{GuHCl}$ (Fig. 6A) had an irreversible nature with a gradual rise in the current, even at $-0.2 \mathrm{~V}$. The irreversible nature, however, was greatly improved in the presence of $\mathrm{GuHCl}$ at a relatively low concentration $(100 \mathrm{mM})$, and the limiting current was attained at $-0.1 \mathrm{~V}$

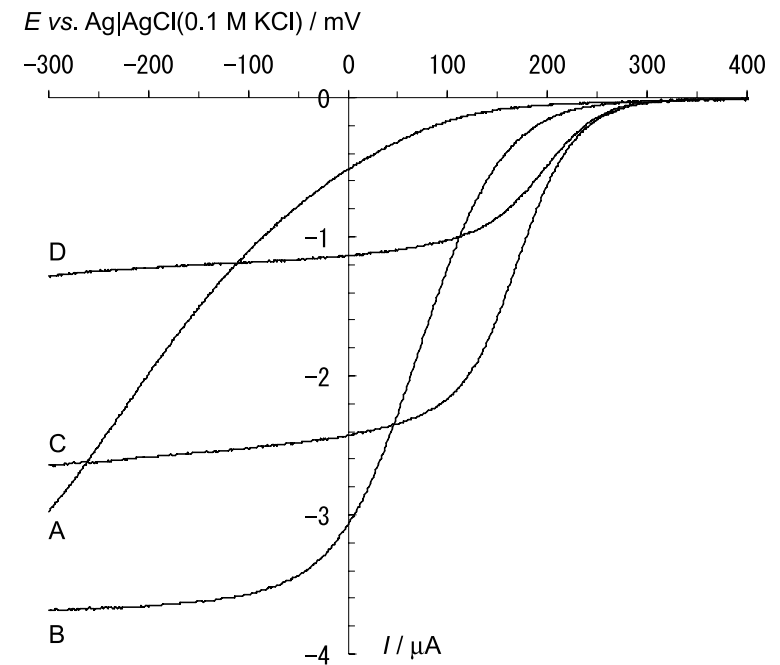

Fig. 6 Linear sweep voltammograms recorded with the membrane/BOD/GC electrode at $25^{\circ} \mathrm{C}$ in $50 \mu \mathrm{M} \mathrm{Fe}(\mathrm{CN})_{6}{ }^{3-}$ phosphate buffer ( $\mathrm{pH} 7.0$ ) containing $\mathrm{A}-\mathrm{D}, 0 \mathrm{M}, 0.1 \mathrm{M}, 0.5 \mathrm{M}$, and $1.0 \mathrm{M}$ $\mathrm{GuHCl}$; scan rate, $2 \mathrm{mV} / \mathrm{s}$. The same membrane/BOD/GC electrode was used for recording the four voltammograms, and the solution was stirred with a magnetic stirring bar.

(Fig. 6B). The limiting current was decreased with an increase in $[\mathrm{GuHCl}]$ in a similar manner to Fig. 5.

It is noted that the voltammogram of $\mathrm{Fe}(\mathrm{CN})_{6}{ }^{4-}$, itself, shifts to a more positive potential in the presence of $\mathrm{GuHCl}$ (from a to $\mathrm{b}$ in Fig. 5). The voltammogram for the bioelectrocatalytic reaction shifts to a positive potential accordingly, and the shape of the voltammogram is improved (Figs. 5 and 6). The positive shift would be explained by the difference between the electrostatic affinity with a guanidium ion of $\mathrm{Fe}(\mathrm{CN})_{6}{ }^{3-}$, and that of $\mathrm{Fe}(\mathrm{CN})_{6}{ }^{4-}$, although the liquid junction potential at the interface between the test solution and the $0.1 \mathrm{M} \mathrm{KCl}$ reference electrode might be involved in the potential shift at such a high concentration of $\mathrm{GuHCl}$ as $1 \mathrm{M}$. More information about the latter effect would be obtainable by a series of measurements with reference electrodes of different $\mathrm{KCl}$ concentrations. In any event, the improvement of the voltammetric shape is attributed to the acceleration of the electrode reaction rate of the $\mathrm{Fe}(\mathrm{CN})_{6}{ }^{3-} / \mathrm{Fe}(\mathrm{CN})_{6}{ }^{4-}$ couple in the presence of $\mathrm{GuHCl}$. Figures 5 and 6 demonstrate that the BOD activity is decreased by $\mathrm{GuHCl}$, and that the effect of $\mathrm{GuHCl}$ is similar both in solution and in the immobilized-state on the electrode. It should be mentioned, however, that it is rather difficult to obtain reproducible results in measurements at the membrane/BOD/GC electrode. Seven measurements at different membrane/BOD/GC electrodes resulted in a decrease in $I_{1}$ from 50 to $30 \%$ at $[\mathrm{GuHCl}]=1 \mathrm{M}$.

Unfolding (denaturation) by denaturants $(\mathrm{GuHCl}$ and urea) is a well-known fact $^{23 a}$ for many proteins, which have been measured by a number of spectroscopic methods, such as fluorescence spectroscopy, ${ }^{23 b} \mathrm{UV}$ absorption spectroscopy ${ }^{23 \mathrm{c}}$ and CD spectroscopy. ${ }^{23 \mathrm{~d}}$ These spectroscopic methods measure the structural changes upon unfolding by $\mathrm{GuHCl}$ or urea; the changes are local to the tryptophan ${ }^{23 a-c}$ and tyrosine ${ }^{23 c, d}$ residue(s), and in the secondary structures of a protein molecule. ${ }^{23 \mathrm{~d}}$ The structural change of an enzyme would cause inactivation of the enzyme. The $\mathrm{CD}$ measurement of $\mathrm{BOD}$ revealed, however, that the $\mathrm{CD}$ spectrum was little affected by the addition of $\mathrm{GuHCl}$ at a concentration of $1 \mathrm{M}$, at which the BOD activity was significantly decreased (Figs. 5 and 6). The 


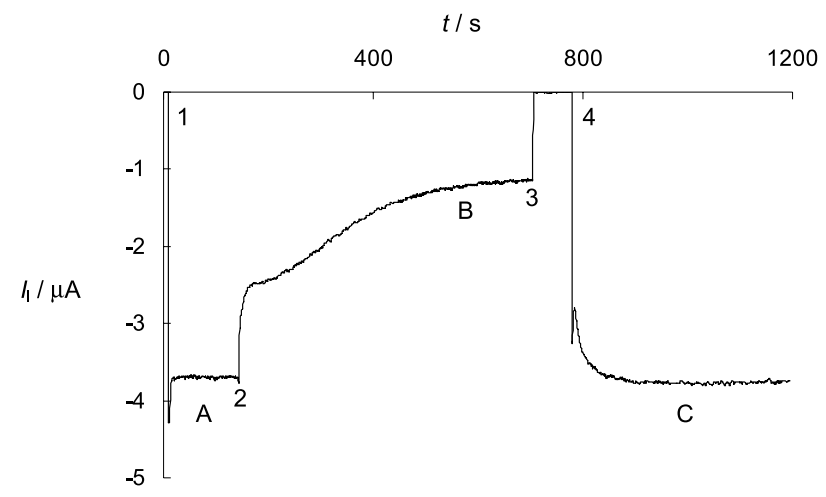

Fig. 7 Change in $I_{1}(-0.2 \mathrm{~V})$ at the membrane/BOD/GC electrode at $25^{\circ} \mathrm{C}$ caused by the addition or removal of $\mathrm{GuHCl}$. (1) The solution was initially $50 \mathrm{mM}$ phosphate buffer containing $50 \mu \mathrm{M} \mathrm{FeCN}_{6}{ }^{3-}$ and $50 \mathrm{mM} \mathrm{GuHCl}$, and the circuit was closed at 1 ; (2) $4 \mathrm{M} \mathrm{GuHCl}$ containing $50 \mu \mathrm{M} \mathrm{FeCN}_{6}{ }^{3-}$ was added at 2 to make the solution $1 \mathrm{M}$ in the $\mathrm{GuHCl}$ concentration; (3) the circuit was opened at 3; (4) the solution was changed to the phosphate buffer containing $50 \mu \mathrm{M}$ $\mathrm{FeCN}_{6}{ }^{3-}$ and $50 \mathrm{mM} \mathrm{GuHCl}$, and the circuit was closed at 4 .

results suggest that the activity of BOD is sensitive to a structural change of the BOD that is not detectable by CD measurements.

The unfolding of a protein by $\mathrm{GuHCl}$ and urea is known to be a reversible process, and the time required to reach the folding/unfolding equilibrium can range from milliseconds to days, depending on the protein and conditions. ${ }^{23 a, 24}$ We studied the effect of the addition or removal of $\mathrm{GuHCl}$ on the bioelectrocatalytic current at a membrane/BOD/GC electrode at $-0.2 \mathrm{~V}$ (Fig. 7). Figure 7A is the current that was measured at $-0.2 \mathrm{~V}$ in a solution containing $50 \mu \mathrm{M} \mathrm{Fe}(\mathrm{CN})_{6}{ }^{3-}$ and $50 \mathrm{mM}$ $\mathrm{GuHCl}$. The presence of $\mathrm{GuHCl}$ at a low concentration improved the shape of the voltammogram, as mentioned above (Figs. 5 and 6 ), assuring that the current at $-0.2 \mathrm{~V}$ was a limiting current, $I_{1}$. When the solution was brought to $1 \mathrm{M} \mathrm{GuHCl}$, the current decreased (Fig. 7B) as expected from Fig. 6, but in a complex way; first, a sharp decrease in $I_{1}$ occurred, and then a gradual decrease followed. When the solution was changed to that of the original composition $\left(50 \mu \mathrm{M} \mathrm{Fe}(\mathrm{CN})_{6}{ }^{3-}\right.$ and $50 \mathrm{mM}$ $\mathrm{GuHCl}$ ), $I_{1}$ returned to the original magnitude (Fig. 7C). This result clearly shows the reversible nature of the effect of $\mathrm{GuHCl}$. Figure 7 also shows that the changes in the BOD activity are rather fast processes under the present experimental conditions, except for the slow second step after the addition of $1 \mathrm{M} \mathrm{GuHCl}$ (from 2 to 3 in Fig. 7). This slow step was not observed when $0.3 \mathrm{M} \mathrm{GuHCl}$ was added.

\section{Effects of $\mathrm{GuHCl}$ on thermal inactivation}

We previously measured thermal inactivation of BOD and determined the kinetic parameters for the inactivation reaction. ${ }^{6}$ In the present study, the thermal inactivation of BOD was measured in the same manner in the presence of $0.3 \mathrm{M} \mathrm{GuHCl}$. The measurement would be helpful for obtaining more information on the $\mathrm{GuHCl}$ effect mentioned above. Figure 8 shows Arrhenius plots for the reaction in the absence (A) and presence (B) of $0.3 \mathrm{M} \mathrm{GuHCl}$. The $k$ values on plot $\mathrm{B}$ are larger than those on plot $\mathrm{A}$, indicating that $\mathrm{GuHCl}$ accelerates the thermal inactivation. Thus, we may say that $0.3 \mathrm{M} \mathrm{GuHCl}$ affects not only the activity of BOD, but also the stability of BOD. The Arrhenius activation energy $\left(E_{\mathrm{A}}\right)$ was calculated from the slope of plots A and B as 219 and $151 \mathrm{~kJ} \mathrm{~mol}^{-1}$, respectively. The values of the Gibbs activation energy $\left(\Delta G^{\neq}\right)$,

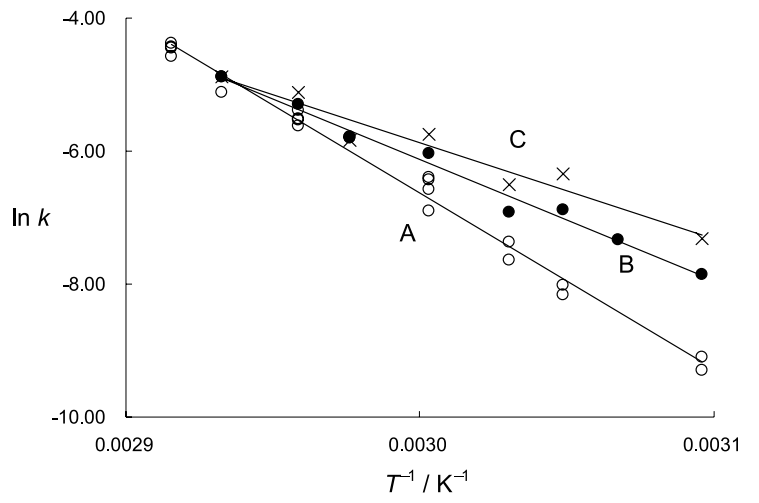

Fig. 8 Arrhenius plots of the rate constant $k$ for the thermal inactivation of BOD in A, $50 \mathrm{mM}$ phosphate buffer $(\mathrm{pH} \mathrm{7.0)}$ ) and $\mathrm{B}$, $50 \mathrm{mM}$ phosphate buffer $(\mathrm{pH} 7.0)$ containing $0.3 \mathrm{M} \mathrm{GuHCl} . \mathrm{C}$ is a plot of the rate constant, $k_{\mathrm{n}}$ (see text).

Table 1 Arrhenius activation energy and kinetic parameters for the thermal inactivation of BOD in the absence and presence of $\mathrm{GuHCl}$ at $\mathrm{pH} 7.0$ (50 mM phosphate buffer)

\begin{tabular}{lcccc}
\hline & $\begin{array}{c}E_{\mathrm{A}} / \\
\mathrm{kJ} \mathrm{mol}^{-1}\end{array}$ & $\begin{array}{c}\Delta G^{\neq \mathrm{b}} \\
\mathrm{kJ} \mathrm{mol}^{-1}\end{array}$ & $\begin{array}{c}\Delta H^{\ddagger} / \\
\mathrm{kJ} \mathrm{mol}^{-1}\end{array}$ & $\begin{array}{c}\Delta S^{\neq} / \\
\mathrm{J} \mathrm{mol}^{-1} \mathrm{~K}^{-1}\end{array}$ \\
\hline $\mathrm{No} \mathrm{GuHCl}$ & 219 & 100 & 216 & 347 \\
$\mathrm{GuHCl}(0.3 \mathrm{M})$ & 151 & 99 & 148 & 147 \\
$k_{\mathrm{n}}{ }^{\mathrm{a}}$ & 120 & 98 & 118 & 59 \\
\hline
\end{tabular}

a. see text.

b. $\Delta G^{\neq}$is the value at $60^{\circ} \mathrm{C}$.

activation enthalpy $\left(\Delta H^{\neq}\right)$, and activation entropy $\left(\Delta S^{\ddagger}\right)$ for the respective inactivation reaction were calculated in the same way as described previously. ${ }^{6}$ The results are summarized in Table 1.

The $E_{\mathrm{A}}, \Delta G^{\neq}, \Delta H^{\neq}$and $\Delta S^{\neq}$values for the inactivation of BOD in the absence of $\mathrm{GuHCl}$ are all within the reported range for the respective quantities for the thermal inactivation of a number of enzymes. ${ }^{25}$ The $\mathrm{CD}$ spectral change during the thermal inactivation (Fig. 3) and the three dimensional structure of $\mathrm{BOD}^{22}$ support the idea that the large $\Delta H^{\neq}$and $\Delta S^{\neq}$values can be attributed to the cleavage of many numbers of weak non-covalent bonds within a native BOD molecule, and an increasing local disorder in the inactivation process, respectively. A large positive value of $\Delta S^{\neq}$for enzyme inactivation is briefly discussed in Ref. 25.

The $\Delta H^{\ddagger}$ and $\Delta S^{\neq}$values significantly decreased in the presence of $0.3 \mathrm{M} \mathrm{GuHCl}$, while the $\Delta G^{\ddagger}\left(60^{\circ} \mathrm{C}\right)$ value was little altered by the denaturant, because of decreases of two quantities, $\Delta H^{\ddagger}$ and $\Delta S^{\neq} T$, in a comparable magnitude (Table 1). There are two possible explanations for the effect of $\mathrm{GuHCl}$. The first is based on a model of multiple equilibria between the BOD and guanidium ion $(\mathrm{G})$ : $\mathrm{BOD}+\mathrm{G} \leftrightarrow \mathrm{BOD}-\mathrm{G}+\mathrm{G} \leftrightarrow \mathrm{BOD}-2 \mathrm{G}+\mathrm{G}$ $\leftrightarrow \cdots \leftrightarrow$ BOD- $n \mathrm{G}$. When the $n$ combining sites are identical and have no effect upon one another, the average number of molecules, G, associated with each BOD molecule $(v)$ is given by $v=n K[\mathrm{G}] /(1+[\mathrm{G}])$, where $K$ and $[\mathrm{G}]$ denote the equilibrium constant and the concentration of $\mathrm{G}$, respectively. ${ }^{26}$ The binding of $\mathrm{G}$ to BOD would cause a small structural change, a change not detectable by $\mathrm{CD}$ measurements, but resulting in a decrease in the $\Delta H^{\neq}$and $\Delta S^{\neq}$values. The structural change would become more significant with increasing concentration of $\mathrm{GuHCl}$, and thus the activity and stability become lower with increasing 
concentration of $\mathrm{GuHCl}$.

The second explanation is one that assumes equilibrium between native (catalytically active) BOD and an inactive $\mathrm{BOD} ;{ }^{27}$ the two forms of BOD are not distinguishable by $\mathrm{CD}$ measurements. The BOD inactivation process in the presence of $\mathrm{GuHCl}$ may be written as

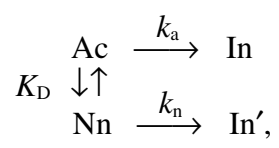

where Ac, $\mathrm{Nn}$ and $\mathrm{In}\left(\mathrm{In}^{\prime}\right)$ are active, non-active and inactive forms of BOD, respectively, and $K_{\mathrm{D}}$ is the equilibrium constant

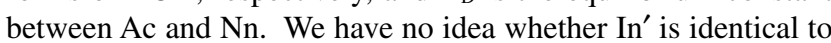
In or not. Only Ac is catalytically active, and Ac and $\mathrm{Nn}$ are in an equilibrium state in the presence of $\mathrm{GuHCl}$, the ratio being dependent on the concentration of $\mathrm{GuHCl}$. The $k$ values of plot A in Fig. 8 correspond to the rate constant $k_{\mathrm{a}}$ in Eq. (5), and the $k$ values of plot $\mathrm{B}$ to the quantity $\left(K_{\mathrm{D}} k_{\mathrm{n}}+k_{\mathrm{a}}\right) / 2$. The $K_{\mathrm{D}}$ value could be estimated to be close to unity from the extent of the decrease in the bioelectrocatalytic current at $[\mathrm{GuHCl}]=0.3 \mathrm{M}$ : $I_{1}(0.3 \mathrm{M} \mathrm{GuHCl}) / I_{1}=0.7$ (data not shown). Noting that $I_{1}$ is proportional to $[\mathrm{BOD}]^{1 / 2}$, we obtain $\left(I_{1}(0.3 \mathrm{M} \mathrm{GuHCl}) / I_{1}\right)^{2}=$ $1 /\left(1+K_{\mathrm{D}}\right)=0.49$ (the equilibrium constant is rather insensitive to temperature, as mentioned above (see Fig. 5)). Thus, the quantity $K_{\mathrm{D}} k_{\mathrm{n}}+k_{\mathrm{a}}$ may be written as $k_{\mathrm{n}}+k_{\mathrm{a}}$ in the first-order approximation, and the $k_{\mathrm{n}}$ value is calculated from $k_{\mathrm{n}}=2 k-k_{\mathrm{a}}$. An Arrhenius plot of $k_{\mathrm{n}}$ is shown as plot $\mathrm{C}$ in Fig. 8, and the values of $\Delta G^{\neq}, \Delta H^{\neq}$and $\Delta S^{\neq}$are given in Table 1. The results show that the $\Delta H^{\neq}$and $\Delta S^{\neq}$values for the thermal inactivation from non-active form $(\mathrm{Nn})$ to $\mathrm{In}^{\prime}$ are greatly decreased as compared with those from the native (catalytically active) BOD (Ac) to In. We may consider that the transition states for the thermal inactivation of $\mathrm{Ac}$ and for that of $\mathrm{Nn}$ are very similar. Consequently, the large decreases in the $\Delta H^{\ddagger}$ and $\Delta S^{\ddagger}$ values should be attributed to the difference in the structure between Ac and Nn. It seems difficult, however, to assume a structure that allows such a large change in the $\Delta H^{\ddagger}$ and $\Delta S^{\neq}$values without a change in the secondary structure. Thus, the first explanation seems to be preferable to the second, although we have no quantitative explanation for the decreases of $68 \mathrm{~kJ} \mathrm{~mol}^{-1}$ in $\Delta H^{\ddagger}$ and $200 \mathrm{~J} \mathrm{~mol}^{-1} \mathrm{~K}^{-1}$ in $\Delta S^{\neq}$.

\section{Conclusion}

The electrochemical method based on bioelectrocatalytic currents allowed measurements of the kinetics and thermodynamics of BOD inactivation by heat and $\mathrm{GuHCl}$. Thermal inactivation is an irreversible process accompanied by a structural change that is detectable by spectroscopic measurements. Inactivation by $\mathrm{GuHCl}$ is a reversible process with a structural change not detectable by CD measurements The electrochemical method will be applicable to studies of the inactivation of other redox enzymes and evaluations of their stability both in solution and in an immobilized state.

\section{Acknowledgements}

The author (T. I.) wishes to exppress his thanks to Amano Enzyme Inc., Nagoya, Japan for the kind gift of BOD. Financial supports by Sony Co. and Toyota Central Institute are greatly appreciated.

\section{References}

1. "Kouso Kougaku (Enzyme Technology, in Japanese)", ed. S. Fukui, I. Chibata, and S. Suzuki, 1981, Tokyo-kagaku-dojin, Tokyo.

2. "Baiodenkikagaku no Jissai, Baiosensa.Baiodenchi no Jitsuyou Tenkai (Practical Bioelectrochemistry, Recent Developments in Biosensors \& Biofuel Cells, in Japanese)", ed. T. Ikeda, 2007, CMC Publishing, Tokyo, 62.

3. K. Hiromi, "Kouso Hannou Kaiseki no Jissai (Practice in Kinetic Analysis of Enzyme Reactions, in Japanese)", 1989, Koudansya, Tokyo.

4. K. Kano and T. Ikeda, Bunseki (in Japanese), 2003, 576.

5. K. Kano and T. Ikeda, Electrochemistry, 2003, 71, 86.

6. T. Ikeda, H. Tatsumi, H. Katano, M. Wanibuchi, T. Hibi, and T. Kajino, Anal. Sci., 2008, 24, 237.

7. T. Ikeda, H. Hamada, K. Miki, and M. Senda, Agric. Biol. Chem., 1985, 49, 541.

8. D. Iswantini, K. Kano, and T. Ikeda, Biochem. J., 2000 $350,917$.

9. H. Shin, C. Kang, and A. Heller, Electroanalysis, 2007, 19, 638.

10. S. Koikeda, K. Ando, H. Kaji, T. Inoue, S. Murao, K. Takeuchi, and T. Samejima, J. Biol. Chem., 1993, 268, 18801.

11. A. Shimizu, J. H. Kwon, T. Sasaki, T. Satoh, N. Sakurai, T. Sakurai, S. Yamaguchi, and T. Samejima, Biochemistry, 1999, 38, 3034.

12. A. Shimizu, T. Sasaki, J. H. Kwon, A. Okada, T. Satoh, N. Sakurai, T. Sakurai, S. Yamaguchi, and T. Samejima, J. Biochem., 1999, 125, 662.

13. S. Murao and N. Tanaka, Agric. Biol. Chem., 1981, 45, 2383.

14. T. Ikeda, Chem. Rec., 2004, 4, 192.

15. S. C. Barton, J. Gallaway, and P. Atanasov, Chem. Rev., 2004, 104, 4867

16. T. Nakagawa, S. Tsujimura, K. Kano, and T. Ikeda, Chem. Lett., 2003, 32, 54.

17. S. Tsujimura, M. Kawaharada, T. Nakagawa, K. Kano, and T. Ikeda, Electrochem. Commun., 2003, 5, 138.

18. R. Matsumoto, K. Kano, and T. Ikeda, J. Electroanal. Chem., 2002, 535, 37.

19. M. Senda, T. Ikeda, H. Hiasa, and I. Katasho, Nihon Kagaku Kaishi (in Japanese), 1987, 358.

20. T. Ikeda, K. Miki, and M. Senda, Anal. Sci., 1988, 4, 133.

21. Y. Gotoh, Y. Kondo, H. Kaji, A. Takeda, and T. Samejima, J. Biochem., 1989, 106, 621.

22. K. Sagara, A. Sato, Y. Kamitaka, S. Tsujimura, K. Mizutani, N. Takahashi, Y. Nakanishi, T. Sugiura, S. Yamaguchi, K. Kano, and B. Mikami, Presented at the 2008 Annual Meeting of Japan Society for Bioscience, Biotechnology, and Agrochemistry at Nagoya, 2008, Abstract No. 3A08p09, 195.

23. (a) B. A. Shirley, "Methods in Molecular Biology", ed. B. A. Shirley, 1995, Vol. 40, Humana Press Inc., Totowa NJ, 177. (b) C. A. Royer, ibid., 65. (c) H. Mach, D. B. Volkin, C. J. Butke, and C. R. Middaugh, ibid., 91. (d) K. Kuwajima, ibid., 115.

24. J. Walters, S. L. Milam, and A. C. Clark, "Methods in Enzymology", ed. M. L. Johnson, J. M. Holt, and G. K. Ackers, 2009, Vol. 455, Elsevier, 1.

25. I. H. Segel, "Enzyme Kinetics", 1993, John Wiley \& Sons, Inc., New York, 941.

26. C. Tanford, "Physical Chemistry of Macromolecules", 1961, John Wiley \& Sons, INC, New York, 634.

27. T. E. Creighton, Biochem. J., 1990, 270, 1. 